\title{
A Benchmarking Tool to Assess the Role of the Construction Manager in terms of Project Teamwork Supports
}

\author{
Kim, Chan-Kyu* \\ Department of Architectural Engineering, Sunmoon University, TangJung-Myun, Asan city, 336-708, Korea
}

\section{Abstract}

Construction management services have been adopted for more than a decade and are continuously growing; however, the advantages of utilizing a construction management service are still not quite clear, regardless of many arguments can be made in their favor. The construction manager, as a coordinator, is supposed to smoothly facilitate the project teamwork in order to deliver a profitable and satisfactory project, not only for the owner's interests but also for the success of all project participants. This study has focused on the teamwork supports a construction manager can provide during project operations. This study developed a benchmarking tool to assess the construction manager's role in terms of its project teamwork supports, by utilizing the evaluation model and several case studies. In addition, this study also attempted to set the industry average and higher performance so that both the owner and the construction manager can self-assess, and more importantly, can improve project operation. The actual implementation of the benchmarking tool into on-going projects can allow the construction manager to understand the current operation and to make a better project process through teamwork.

Keywords : Benchmarking, Teamwork, Construction Manager

\section{Introduction}

Construction management service was introduced by Framework Act on the Construction Industry in 1996. After on, construction management has been gradually growing. The sale amount of construction management service before 2001 was merely about 40 million dollars, and the sale of year between 2001 and 2002 was around 90 million dollars. However the entire sale of construction management service between year 2007 and 2008 was over 9 billion dollars[1]. It represents construction management service has grown more than fifteen times as much as it was ten years ago. Not only the sale amount of construction management

Received : February 22, 2011

Revision received : March 8, 2011

Accepted : March : March 10, 2011

* Corresponding author: Kim, Chan-Kyu

[Tel: 82-41-530-2378, E-mail: qkim@sunmoon.ac.kr]

(c)2011 The Korea Institute of Building Construction, All rights reserved. service but also the role of it has been refurbished. The first construction management service applied to World Cup Stadium in 1999 was not much different from the one of traditional superintendence job, which was regulated by law. However, construction management service has been evolving from that time on. It has gradually consumed such tasks as design review, value engineering, permits, feasibility studies, financial aids, sale promotion and so on[2]. This could provide the great opportunities for both owner and construction manager to create a profitable or satisfactory project outcome. Even constructor could see construction manager not as an obstructer but as a helper. However, the advantages of utilizing construction management service are not quite clear so far regardless of many arguments. Some say cost-effective and some say time-efficient. Research finding these advantages of construction management use has not been conducted yet leaves much to be required. 
In Korean construction industry, there are apparent limitations of construction manager to exercise its role. Construction manager in accordance to the contract has no rights to control scope, budget, and schedule. And it is not even allowed to decide the upper limits and lower limits of project quality. Consequently it is not probable or fair to assess construction manager by project cost or time. Many projects have frequently resulted in over budget and schedule regardless of construction management use. But sometimes when a project goes wrong, construction manager is but to blame. Then what are the advantages of exploiting construction management service? What is the use of construction manager? Construction manager is the only one in the project that has no conflict while the other participants have their own. Therefore, It is evident that construction manager, as a coordinator, has to make project participants work together. Construction manager is supposed to lubricate or facilitate project teamwork so as to deliver a desirable outcome for the owner' $s$ interests and to meet the other project participants' goal. To make project team together lots of ability and experience are required. This study has focused on the teamwork support of construction manager because it is believed to be a key role of construction manager.

\section{Objective and Methodology}

This study is to develop a benchmarking tool to assess construction manager in terms of project teamwork supports. And it also attempts to set the current industry average and superior performance to self-assess and more importantly improve the project operations. By doing so, the owner will trust construction manager better and construction manager is able to lead the entire project team and hopefully produce a win-win situation among the project participants. This study includes the three activities; to develop an evaluation model to assess the teamwork supports of construction manager, to run several case studies in order to adapt and adjust the developed model, and to implement the benchmarking tool into on-going project for improving project operations.

\section{Development of Evaluation Model}

Teamwork is defined in many ways. It is a work performed by a team toward a common goal[Webster Dictionary]. The interdisciplinary sharing of knowledge, information and goals among the participants(i.e., according to Pietroforte[3]). Seamless Process[4]. The integrated efforts for the project success(i.e., according to Levitt[7]. The innovative alignment for integration [8] and so on. To induce attributes of teamwork the following model is introduced. Figure 1 shows the teamwork process in sequence. This model illustrates the procedure of how teamwork is accomplished. The procedure is presented in order from (a) to (f). Each rectangular shown represents the aggregation of all tasks required to execute the project jobs. The first (a) is in the state full of job remaining in the beginning. Then in stage (b), party A comes in the project and takes some portion of tasks, but still many tasks are remaining unassigned. At this stage the first attribute of teamwork is derived, which is competence. A specialist with expertise and experience has to arrive to take certain tasks. In stage (c), other two parties come in the project to take the rest of jobs remaining. So there are no more dark areas. The second attribute can be derived as agreement of the specialists to abide by the rules to complete their tasks by contractual agreement. Otherwise the project could be ambiguous state which 
task is whose. However, as it is shown in the figure, duplications and redundancies of tasks still exit. In stage (d), arrangement is made among the participants. There are no more duplicative tasks. To reach this stage derive the third attribute is introduced as coordination which is an alignment to organize the process and to define scope preventing the specialist from being confused.

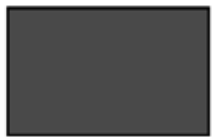

(a)

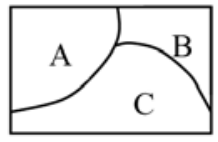

(d)

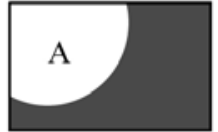

(b)

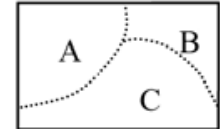

(e)

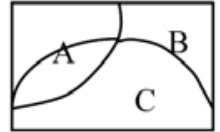

(c)

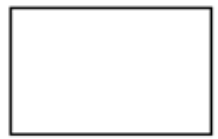

(f)
Figure 1. Teamwork Process Model

The state $(d)$ is not still representing a state of good teamwork because of seams between parts. These seams are interpreted as barriers which obstruct the understandings of each other. What can resolve these barriers? It is the exchange of information. Communication defined as "to give or exchange information" is introduced as the fourth attribute. The complete and correct information flowing through project participants makes it possible to transfer the work load efficiently. Through communication the stage (e) is reached, however, the act of exchange information cannot solely remove the barriers. As you can see, there are still remaining barriers even though they are not as vivid as they were in stage (d). The reason is assumed that because each party has its own interests and is characterized as its own goals. But the desirable teamwork operation has to be accomplished to arrive at the stage (f) of which definition is integration. The results of CII task force are utilized in this stage. It reported that partnering alliance requires trust and sharing common goal[CII, 1996]. Therefore, trust and congruence are derived as the fifth and sixth attributes. The composition of teamwork attributes consists of three aspects as shown Figure 2, people, management, and technique. Congruence and trust are related to people, agreement and coordination and are related managerial aspects, and competence and communication are related to technical aspects of the project. Table 1 represents the identified attributes of project teamwork. This study tried to define each attributes specifically with according sub-attributes. Definitions represented here is concentrated on the teamwork supports of construction manager, however this model can be used for any other project participants or the whole team. Based on this developed evaluation model, case studies has been conducted to verify the model acceptable and to adjust the model into a practical forms.

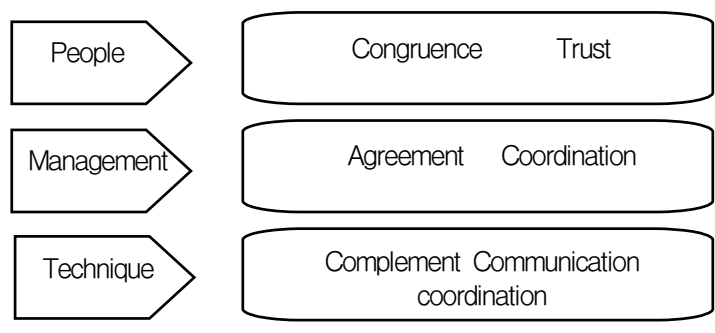

Figure 2. The Composition of Teamwork Attributes

\section{Case studies}

Case studies were conducted in order to achieve the following objectives. First, the developed evaluation model should be validated and adjusted for the actual implementation. Second, among the attributes, there should be a certain ranking system, because all the attributes are not supposed to be measured equally. Some attributes are more important than the others. Therefore a statistical 
Table 1. The Attributes of Project Teamwork

\begin{tabular}{|c|c|c|}
\hline Attributes & Sub-Attributes & descriptions \\
\hline Competence (A1) & $\begin{array}{l}\text { Characteristic } \\
\text { Expertise } \\
\text { Experience } \\
\text { Technical ability }\end{array}$ & $\begin{array}{l}\text { The nature or talent to fully execute certain tasks } \\
\text { Professions directly related toward the specialized work } \\
\text { The achievement of previous practice and participations } \\
\text { Sufficiency in understanding for the required works }\end{array}$ \\
\hline \multirow{5}{*}{ Agreement (A2) } & Scope of work & $\begin{array}{l}\text { Conformity to specifications and appropriate compliance with change } \\
\text { and modification }\end{array}$ \\
\hline & Project schedule & $\begin{array}{l}\text { Awareness and conformity to project schedule and proper execution for } \\
\text { delay and revision }\end{array}$ \\
\hline & Construction method & Consistent operation or procedure to pre-determined methods \\
\hline & Procurement & $\begin{array}{l}\text { Agreement in selecting subcontractors, vendors. Suppliers and } \\
\text { equipment }\end{array}$ \\
\hline & Quality assurance & Awareness and conformity to the project quality assurance \\
\hline \multirow{7}{*}{ Coordination (A3) } & Organization structure & The appropriate arrangement of functional relationship \\
\hline & Construction management & The existence of construction management manual or \\
\hline & manual & procedure to execute project management \\
\hline & Administration & The management and settlement of official execution \\
\hline & Approving procedure & $\begin{array}{l}\text { The effective arrangement of approving and receiving procedures of } \\
\text { drawings, documents, and payments }\end{array}$ \\
\hline & Reporting System & The judicious and adequate use of reporting system \\
\hline & Change procedure & Utilization of procedure for necessary change and modification \\
\hline \multirow{4}{*}{ Communication (A4) } & Clearness & Clarity in exchange information and sharing data \\
\hline & Completeness & Completeness of information among the participants \\
\hline & Correctness & Correctness of distributes information \\
\hline & Punctuality & Availability of information on time \\
\hline \multirow{4}{*}{ Congruence (A5) } & Project objectives & Awareness and conformity to the project objectives and goals \\
\hline & Involvement & Participation in resolving issues and problem solving \\
\hline & Eagerness & An attitude with voluntary cooperation \\
\hline & Devotion & Concentrated efforts regarding resolving issues and problems \\
\hline \multirow{3}{*}{ Trust (A6) } & Openness & $\begin{array}{l}\text { Freely communicating ideas and expressing them without fear of } \\
\text { repercussion }\end{array}$ \\
\hline & Flexibility & Flexibility in dealing with particular job circumstances \\
\hline & Fairness & Fair and just treatment of other party in all areas of the project \\
\hline
\end{tabular}

analysis to decide weight factor has to be made.

Third, implementation of the developed model into the recently accomplished projects, where construction management service was adopted, should be provided in order to assess the teamwork support of construction manager. And fourth, from the observe data of case studies the attempted industry average and superior performance has to be made so that the evaluation model can be utilized as a benchmarking tool. And finally with this tool, one more case study for the on-going project should be conducted to see how this model could help owner or construction manager improve the project operations. Table 2 shows the projects involved in case studies. All these projects acquired construction management service and were accomplished recently. Case study was conducted via interviews, questionnaire, phone, email, and exchanging of evaluation model. Spreading massive questionnaire is not appropriate to this kind of study, therefore case studies were conducted on a personal contact basis. Total 46 
Table 2. The projects of Case Studies

\begin{tabular}{|c|c|c|c|c|}
\hline Project Name & Location & Budget $(\$)$ & Duration & Owner \\
\hline Sun Maeul & HongChun, Kang-Won & 22 million & 2005.4 2007. 11 & Daewoong Inc. \\
\hline Kwang-Joo City Hall & Kwang-Jooo, Chun-Nam & 48 million & $2007.2 \sim 2009.4$ & Kwang-Joo City \\
\hline Osung Bio Center & Osung, Chung-Nam & 430 million & 2007.5 2010. 10 & $\begin{array}{c}\text { The Health and Welfare } \\
\text { Administration }\end{array}$ \\
\hline $\begin{array}{l}\text { Inchon University } \\
\text { Relocation }\end{array}$ & Song-Do, Inchon & 237 million & $2008.2 \sim 2010.10$ & Inchon City \\
\hline Dream Forrest & Sung-Buk, Seoul & 41 million & $2006.6 \sim 2008.9$ & Seoul City \\
\hline Nurikun Square & Sang-Am, Seoul & 196 million & $2007.11 \sim 2010.10$ & Sang-Am Electronic \\
\hline Hiwon Condominium & Jung-Sun, Kang-Won & 200 million & $2007.4 \sim 2010.8$ & Kang-Won Land \\
\hline Tower Hotel Remodel & Jang-Chung, Seoul & 60 million & $2007.5 \sim 2010.3$ & Urban Oasis \\
\hline
\end{tabular}

members of those projects, who were in charge of actual operations, including owner, construction manager, constructor, and designer, were in contact to validate the model and to decide weight factors. But the actual assessment of construction manager was made solely by the owners because of consistency and fairness. And the author had really hard time getting in contact with the owners of the projects where the case studies were involved.

Around $76 \%$ of the response agreed on the developed evaluation model as acceptable to use assess the teamwork supports of construction manager. However, a subjectivity issue of this model was occurred among the responders. So It is required that a certain measurement method or tool exist. Quantification of measurement would be good for evaluation, but the most are not quite possible. Thus the model was divided into two ways, which are a subjective measurement and a quantifiable measurement. Even it is a subjective measurement, the status or environment of the score given was stated. Table 3 is an example of measurement for project objective attribute. The state of construction manager' $\mathrm{s}$ efforts was described according to the score given. By using this statement, responders are able to give the score in conformity without prejudice or confusion.
Table 3. The Subjective Measurement of Project Objective Attributes

Project Objective

Construction Manager is to :

Fully understand the project goals and exert leadership to avoid conflict interests and to attain $9 \sim 10$ common goals among the participants

Meet owner's objectives and persuade the other participants into aligning common goals

Struggle in coping with owner's objectives and fails to make participants understand the project objectives

Be not quite aware of owner's objectives and makes little efforts to communicate with other project $0 \sim 2$ participants

The example of quantifiable measurement is illustrated in Figure 3 showing approving procedure sub-matrix. Approving procedure, sub-attribute of coordination can be measured by several observations such as wrongdoings of construction manager. Actually to obtain accurate measurement, it surely requires lots of case studies, but this is providing a general idea of quantitative measurement and is sufficient for responders to grasp the measuring method. The score given in this sub-matrix will be used and added in the higher attribute matrix so that the overall scoring can be presented. Performance index shows the percentage value of the score acquired against the maximum score. 


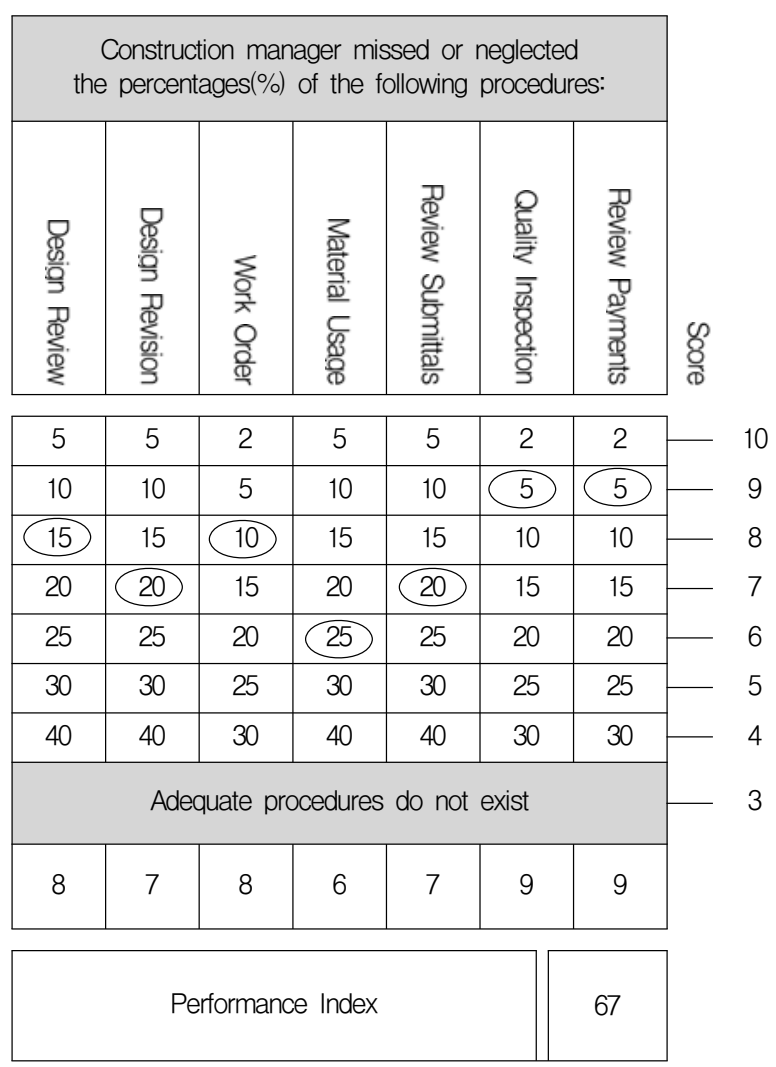

Figure 3. Approval Procedures sub Matrix

The next step of case studies was to find weight factors among the attributes of project teamwork because each attribute are not supposed to count equally. The major participants involved in the projects shown Table 2 helped to estimate weight factors with the response of questionnaire. It was a ranking system which each responder decide the most important attributes in hierarchical order.
Table 4 represents the results showing the designated weight factors for each attributes corresponding to mean value acquired by the responses. The score of weight factors were arranged in order to make the maximum score of 1,000 point in the evaluation system. It was found out interestingly that competence of construction manager was represented as an important attribute of project teamwork supports. Agreement and congruence also were positioned highest in rankings.

Table 4. Mean Value and Weight Factors of Attributes

\begin{tabular}{ccc}
\hline Attributes & Mean Value & Weight Factor \\
\hline Agreement & 14.2 & 2.00 \\
Competence & 10.5 & 1.75 \\
Congruence & 8.6 & 1.64 \\
Coordination & 7.2 & 1.58 \\
Trust & 5.3 & 1.53 \\
Communication & 5.2 & 1.50 \\
\hline
\end{tabular}

\section{The Results and Implementation}

Using adjusted evaluation model and arranging weight factors, the actual assessment was conducted. The eight projects, which were recently accomplished by both public and private sector, were used to evaluate the teamwork contribution of construction manager by the owners. Table 5

Table 5. The Evaluation of Construction Manager's Project Teamwork Supports by Case studies

\begin{tabular}{lccccccccc}
\hline \multicolumn{1}{c}{ Projects } & Attributes & A1 & A2 & A3 & A4 & A5 & A6 & Total & Ranks \\
\hline & 146 & 142 & 129 & 137 & 126 & 119 & 799 & 2 \\
Sun Maeul at Hong Chun, Kang-Won City Hall at & 134 & 146 & 118 & 119 & 96 & 101 & 714 & 7 & 14 \\
Kwang- Joo, Chun-Nam Bio Center at Osung, & 159 & 162 & 143 & 144 & 112 & 114 & 834 & 1 \\
Chung-Nam Inchon Univ. Relocation, Song- Do & 127 & 126 & 120 & 108 & 92 & 106 & 679 & 8 \\
Dream Forrest, Sung- Buk, Seoul Nurikun square, & 148 & 138 & 132 & 124 & 105 & 112 & 759 & 4 \\
Sang- Am, Seoul Hiwon Condominium, Chung -Sun & 132 & 151 & 133 & 121 & 115 & 123 & 775 & 3 \\
Tower Hotel Remodeling, Seoul & 136 & 146 & 128 & 128 & 104 & 106 & 748 & 5 \\
& & 133 & 134 & 128 & 106 & 101 & 119 & 721 & 7 \\
\hline & Average & 139 & 143 & 128 & 123 & 106 & 113 & 753 \\
\hline
\end{tabular}


illustrates the results of case studies. The columns of the table presented the attributes shown in order of Table 1. And numbers given are the scores according to the evaluation model. The darker numbers are the highest score of each attribute and the shaded area represented a superior performance among the projects. Bio Center built in Osung was the best practice of construction manager' s teamwork efforts in the observed case study. The bottom row indicates the percentage value given for each attribute in order to understand the magnitude of the score. 753 points shown at right bottom corner is the average value of evaluation. Coordination(A3) and Communication(A4) acquired relatively higher points than the rest of attributes. Congruence(A5), goal alignment efforts and devotion for project operation, was found to be the most complaint from the owners. The case study of this research contains 8 projects, so it may not be possible to present the industry average and a superior performance. However, judging form that the annual sale amount of construction management service is around 300 400 million dollars only per year, and also as long as the projects observed is current, the data collected here cannot be negligible rather considerable. The actual implementation was conducted having used the results of case studies. The project, to which the developed benchmarking tool was applied, was the expansion job of Seoul Nation University General Hospital in Bun Dang. The project is still in progress, so the benchmarking tool was utilized for both its usability and probability of improving project operations.

The evaluation was accomplished by both owner and construction manager which was thought to be interesting. Table 6 shows the results briefly. Owner' s assessment was 768 points total. This is a little higher than the average of case studies saying construction manager is doing fine. And Congruence(A5) is much higher than the average and close to a superior performance. That explains that owner is somewhat satisfactory of construction manager' $s$ efforts and devotions. However coordination(A3) is lower than the average, which still gives room for improvements. Construction manager is required to check the stated procedures and be on duty of sequential activities.

Table 6. The Assessment of Hospital Expansion

\begin{tabular}{ccccccc}
\hline & A1 & A2 & A3 & A4 & A5 & A6 \\
\hline OWr & 136 & 152 & 114 & 123 & 123 & 120 \\
CMr & 150 & 154 & 121 & 119 & 136 & 128 \\
\hline
\end{tabular}

\section{Conclusion}

The advantages of construction management service are not clearly known. Construction management service in Korean construction industry is not contractually allowed to control cost and schedule of the project. Therefore this study attempted to investigate the teamwork supports of the project construction manager can provide because he is able to exert leadership in project team integration, since knowing that he is in the only one without any conflict interests. This study developed a benchmarking tool through conducting case studies. The developed benchmarking tool can be utilized for the on-going assessments of a construction manager's teamwork supports and for the improvement of the project operations.

\section{References}

1. The Annual Reports of The Korean Construction Management Associations, 2009 . 
2. Cho HH. A diagnosis of the current status and future of construction management, the publishing of Korean Construction Management Associations 2010;11(3):23-25.

3. Pietroforte R. Communication and information in the building delivery process, Journal of Construction Engineering and Management 2004;124(2):73-80.

4. Lee S, Thomas S. Web-based benchmarking system the construction industry, Journal of Construction Engineering Management 2005;131(7):42-49.

5. CII task force, Partnering evolution, CII conference, 1994

6. O’ Brien J. Construction change orders: impact, avoidance, documentation. New York, McGraw-Hill professional, 1998.

7. Mahalingam A, Levitt R. Institutional theory as a framework for analyzing conflicts on projects, Journal of Construction engineering and Management 2007;133(7):26-31.

8. Leicht R, Hunter S, Messner J. Implementing observational research and methods to study team performance in construction management, Journal of Construction Engineering Management 2010;136(1):46-53.

9. Jin HS, Lee BH, Kim JJ. Establishment of new business field in construction management business, Journal of the Korea Institute of Building Construction 2009;10(1): 56-61.

10. Yu I, Ki, K, Jung Y. A benchmarking tool for construction companies, Journal of Management Engineering 2007;23(3): $41-47$. 